\title{
Caffeine enhances the antidepressant-like activity of common antidepressant drugs in the forced swim test in mice
}

\author{
Aleksandra Szopa $^{1} \cdot$ Ewa Poleszak $^{1} \cdot$ Elżbieta Wyska $^{2}$ - Anna Serefko ${ }^{1} \cdot$ \\ Sylwia Wośko ${ }^{1} \cdot$ Aleksandra Wlaź $^{3} \cdot$ Mateusz Pieróg ${ }^{4} \cdot$ Andrzej Wróbel $^{5} \cdot$ Piotr Wlaź $^{4}$
}

Received: 16 June 2015 / Accepted: 2 November 2015 /Published online: 27 November 2015

(C) The Author(s) 2015. This article is published with open access at Springerlink.com

\begin{abstract}
Caffeine is the most widely used behaviorally active drug in the world which exerts its activity on central nervous system through adenosine receptors. Worrying data indicate that excessive caffeine intake applies to patients suffering from mental disorders, including depression. The main goal of the present study was to evaluate the influence of caffeine on animals' behavior in forced swim test (FST) as well as the effect of caffeine $(5 \mathrm{mg} / \mathrm{kg})$ on the activity of six typical antidepressants, such as imipramine $(15 \mathrm{mg} / \mathrm{kg})$, desipramine $(10 \mathrm{mg} / \mathrm{kg})$, fluoxetine $(5 \mathrm{mg} / \mathrm{kg})$, paroxetine $(0.5 \mathrm{mg} / \mathrm{kg})$, escitalopram $(2 \mathrm{mg} / \mathrm{kg})$, and reboxetine $(2.5 \mathrm{mg} / \mathrm{kg})$. Locomotor activity was estimated to verify and exclude false-positive/negative results. In order to assess the influence of caffeine on the levels of antidepressant drugs studied, their concentrations were determined in murine serum and brains using high-performance liquid chromatography. The results showed that caffeine at a dose of 10,20 , and $50 \mathrm{mg} / \mathrm{kg}$ exhibited antidepressant activity in the FST, and it was not related to changes in locomotor
\end{abstract}

Ewa Poleszak

ewa.poleszak@umlub.pl

1 Department of Applied Pharmacy, Medical University of Lublin, Chodźki 1, PL 20-093 Lublin, Poland

2 Department of Pharmacokinetics and Physical Pharmacy, Collegium Medicum, Jagiellonian University, Medyczna 9, PL 30-688 Kraków, Poland

3 Department of Pathophysiology, Medical University of Lublin, Jaczewskiego 8, PL 20-090 Lublin, Poland

4 Department of Animal Physiology, Institute of Biology and Biochemistry, Faculty of Biology and Biotechnology, Maria Curie-Skłodowska University, Akademicka 19, PL 20-033 Lublin, Poland

5 Second Department of Gynecology, Medical University of Lublin, Jaczewskiego 8, PL 20-090 Lublin, Poland activity in the animals. Caffeine at a dose of $5 \mathrm{mg} / \mathrm{kg}$ potentiated the activity of all antidepressants, and the observed effects were not due to the increase in locomotor activity in the animals. The interactions between caffeine and desipramine, fluoxetine, escitalopram, and reboxetine were exclusively of pharmacodynamic character, because caffeine did not cause any changes in the concentrations of these drugs neither in blood serum nor in brain tissue. As a result of joint administration of caffeine and paroxetine, an increase in the antidepressant drug concentrations in serum was observed. No such change was noticed in the brain tissue. A decrease in the antidepressant drug concentrations in brain was observed in the case of imipramine administered together with caffeine. Therefore, it can be assumed that the interactions caffeine-paroxetine and caffeineimipramine occur at least in part in the pharmacokinetic phase.

Keywords Caffeine · Antidepressants · Forced swim test . Pharmacokinetic study $\cdot$ Mice

\section{Introduction}

Caffeine is one of the most frequently used psychoactive substances ingested mainly via food products (Fredholm et al. 1999). What is more, it is applied for therapeutic purposes when combined with analgesics (Andrews et al. 2007; Shapiro 2007) and antihistamines or in dietary supplements for weight loss (Andrews et al. 2007; Barone and Roberts 1996; Burke 2008; Shapiro 2007). Caffeine exhibits a stimulating activity which facilitates physical and mental tiredness and helps to improve thinking process (Nehlig et al. 1992). Caffeine consumption rises every year. Worrying data indicate that excessive caffeine intake applies to patients suffering from mental disorders ( $\geq 750 \mathrm{mg}$ caffeine daily) (Rihs et al. 1996). 
After oral administration, caffeine is absorbed from the gastrointestinal tract into the bloodstream in $99 \%$ (Fredholm et al. 1999). The highest concentration of caffeine in plasma is reached 30-60 min after ingestion. Caffeine easily penetrates the intracellular space. It is distributed to all body fluids, that is, plasma, cerebrospinal fluid, saliva, bile, semen, milk, umbilical cord blood, and organ tissues (Arnaud 2011). Hydrophobic properties of caffeine allow its easy penetration through all biological membranes. The blood-brain barrier does not prevent caffeine (Lorist and Tops 2003). As the fraction bound to plasma proteins is low, almost all of caffeine in blood is present in a pharmacologically active form (Arnaud 2011; Lorist and Tops 2003). The main enzyme responsible for the metabolism of caffeine is the isoenzyme CYP1A2 of cytochrome P450 (Carrillo and Benitez 2000).

Caffeine is not accepted as a standard pharmacological treatment of mood disorders, but it is likely that some people can use it as an antidepressant drug in the early stages of this disease (Casas et al. 2004). It is thus possible to demonstrate the usefulness of caffeine and its derivatives in the treatment of depression. It has been shown that caffeine can reverse the monoaminergic system changes observed in depression, for example, caffeine blocking the $A_{1}$ adenosine receptor subunit may increase the levels of catecholamines and serotonin (5HT) in the central nervous system (CNS) (Fredholm 1995). What seems to be important is the fact that caffeine contributes to an increased 5-HT release in the limbic areas and the release of dopamine (DA) in the prefrontal cortex, which is comparable to the effect obtained with the use of antidepressants (Acquas et al. 2002; Fredholm 1995).

Caffeine exerts its activity on CNS through adenosine receptors for which it acts as an antagonist (Benowitz 1990; Dunwiddie and Masino 2001; Fredholm et al. 1999; Pettenuzzo et al. 2008). It was found in various studies, both in vitro and in vivo, that caffeine affects the activity of endogenous adenosine inhibiting the release of various neurotransmitters in CNS: acetylcholine, $\gamma$-aminobutyric acid (GABA), glutamate, DA, noradrenaline (NA), and 5-HT (El Yacoubi et al. 2003; El Yacoubi et al. 2001; Ferré et al. 1996a; Ferré et al. 1996b; Fisone et al. 2004; Williams 1987).

World Health Organization (WHO) estimated that currently, there are 350 million people around the world suffering from depressive disorders. WHO predictions indicate that by 2020 , depression will be the second of civilization disease causing incapacity. Moreover, the age in which the first symptoms of depressive disorders appear is substantially reduced each year. Due to an increasing number of cases diagnosed with mental illnesses, including depression, interactions between caffeine and other drugs used in pharmacotherapy of these disorders attract more and more attention. The main goal of this study was to assess the effect of caffeine on animals' behavior in the forced swim test (FST), which is a widely used behavioral test in estimating antidepressant properties of drugs. Moreover, we also decided to evaluate the influence of caffeine on the activity of typical antidepressant drugs, i.e., imipramine, and its metabolite desipramine - the tricyclic antidepressants (TCAs) - fluoxetine, escitalopram, and paroxetine - the selective serotonin reuptake inhibitors (SSRIs) - and reboxetine - a selective noradrenaline reuptake inhibitor (SNRI).

\section{Material and methods}

\section{Animals}

The experiment was carried out on naive adult male Albino Swiss mice $(25-30 \mathrm{~g})$ purchased from the licensed breeder (Kolacz, Warsaw, Poland). The animals were housed in the environmentally controlled rooms with a 12-h light/dark cycle, in groups of 10 in standard cages under strictly controlled laboratory conditions - temperature maintained at $21-23{ }^{\circ} \mathrm{C}$ and relative humidity about $45-55 \%$. Throughout the study, the animals were given ad libitum access to water and food. The experiment began after at least 1-week acclimation period in the laboratory conditions and was conducted between 8 a.m. and 3 p.m. to minimize circadian influences. Each experimental group consisted of 7-10 animals. All procedures were conducted in accordance with the European Communities Council Directive of 22 September 2010 (2010/63/EU) and Polish legislation acts concerning animal experimentations. The experimental procedures and protocols were approved by the First Local Ethics Committee at the Medical University of Lublin. Each mouse was used only once.

\section{Drugs}

Caffeine (1,3,7-trimethylxanthine; 5, 10, 20, and $50 \mathrm{mg} / \mathrm{kg}$, Sigma-Aldrich, Poznań, Poland), imipramine hydrochloride (15 and $30 \mathrm{mg} / \mathrm{kg}$, Sigma-Aldrich), desipramine hydrochloride $(10 \mathrm{mg} / \mathrm{kg}$, Sigma-Aldrich), fluoxetine hydrochloride (5 mg/kg, Sigma-Aldrich), escitalopram oxalate $(2 \mathrm{mg} / \mathrm{kg}$, Sigma-Aldrich), paroxetine hydrochloride $(0.5 \mathrm{mg} / \mathrm{kg}$, Abcam Biochemicals, Cambridge, UK), and reboxetine mesylate $(2.5 \mathrm{mg} / \mathrm{kg}$, Abcam Biochemicals) were dissolved in $0.9 \% \mathrm{NaCl}$. The solutions of antidepressants were administered intraperitoneally (i.p.) $60 \mathrm{~min}$ before behavioral testing, whereas caffeine solution was administered i.p. $40 \mathrm{~min}$ before the tests. The doses and pretreatment schedules were selected on those reported in the literature and on the basis of the results of our previous experiments (David et al. 2003; Poleszak et al. 2006; Szewczyk et al. 2002; Szewczyk et al. 2009; Urani et al. 2001). All solutions were prepared immediately prior to the experiment. Animals from the control groups received i.p. injections of the vehicle ( $0.9 \%$ saline). The volume of the vehicle or drug solutions for i.p. administration was $10 \mathrm{ml} / \mathrm{kg}$. 


\section{Forced swim test}

The procedure was carried out on mice, according to the method of Porsolt et al. (1977). Each mouse was placed individually into the glass cylinders (height $25 \mathrm{~cm}$, diameter $10 \mathrm{~cm}$ ) containing $10 \mathrm{~cm}$ of water at $23-25^{\circ} \mathrm{C}$. The animals were left in the cylinder for $6 \mathrm{~min}$. The total duration of immobility was recorded by cumulative stopwatches during the last $4 \mathrm{~min}$ of the 6-min-long testing period. The mouse was judged to be immobile when it ceased struggling and remained floating motionless in the water, making only the movements necessary to keep its head above the water level.

The results obtained in the forced swim test were shown as the arithmetic mean of immobility time of animals in seconds \pm standard error of the mean (SEM) for each experimental group.

\section{Spontaneous locomotor activity}

In order to avoid the risk of obtaining the false-positive/negative effects in the FST caused by a possible influence of tested agents on the locomotor activity, the spontaneous locomotor activity was measured using an animal activity meter OptoVarimex-4 Auto-Track (Columbus Instruments, USA). This actimeter consisted of four transparent cages with a lid (43× $43 \times 32 \mathrm{~cm}$ ), a set of four infrared emitters (each emitter has 16 laser beams), and four detectors monitoring animal movements. After i.p. pretreatment with respective drugs or drug combinations (antidepressants and saline were administered i.p. $60 \mathrm{~min}$, and caffeine i.p. $40 \mathrm{~min}$ before the test), mice were placed individually into the cages for $10 \mathrm{~min}$. Spontaneous locomotor activity was evaluated between the second and the sixth minute, which corresponds with the time interval analyzed in the FST.

The results obtained in this test were presented as the arithmetic average distance that a mouse traveled (in centimeters) \pm SEM for each experimental group.

\section{Determination of antidepressants in serum and brain tissue}

Sixty minutes following administration of the antidepressant drugs with or without caffeine, mice were decapitated to collect biological material for pharmacokinetic studies. The blood was collected into Eppendorf tubes and allowed to clot at room temperature. Subsequently, the blood was centrifuged at 10,000 rpm for $10 \mathrm{~min}$ and serum was collected into polyethylene tubes and frozen at $-25{ }^{\circ} \mathrm{C}$. Immediately after the decapitation, the brains were dissected from the skull, washed with $0.9 \% \mathrm{NaCl}$, and also frozen at $-25{ }^{\circ} \mathrm{C}$.

Serum and brain concentrations of the studied antidepressants were assayed by a high-performance liquid chromatography (HPLC) method. The brains were homogenized in distilled water $(1: 4, w / v)$ with a tissue homogenizer TH220 (Omni International, Inc., Warrenton, VA, USA). For all studied drugs, the extraction from serum and brain homogenates was performed using the mixture of ethyl acetate/hexane $(30: 70, v / v)$. The only exceptions were paroxetine and reboxetine, for which the solvents were mixed at a 50:50 $(v / v)$ ratio. Amitriptyline $(2 \mu \mathrm{g} / \mathrm{ml})$ was used as an internal standard (IS) for desipramine and imipramine, desipramine $(500 \mathrm{ng} / \mathrm{ml})$ for paroxetine and reboxetine, and paroxetine $(200 \mathrm{ng} / \mathrm{ml})$ for fluoxetine and escitalopram. In order to isolate imipramine and desipramine, to serum $(200 \mu \mathrm{l})$ and brain homogenate $(0.5 \mathrm{ml})$ containing these drugs, the IS was added and the samples were alkalized with 100 and $250 \mu \mathrm{l}$ of $4 \mathrm{M} \mathrm{NaOH}$, respectively. Then, the samples were extracted with $5 \mathrm{ml}$ of the extraction reagent by shaking for 20 min (IKA Vibrax VXR, Germany). After centrifugation at $3000 \mathrm{rpm}$ for $20 \mathrm{~min}$ (Universal 32 , Hettich, Germany), the organic layer was transferred to a new tube containing a $200 \mu \mathrm{l}$ solution of $0.1 \mathrm{M}$ $\mathrm{H}_{2} \mathrm{SO}_{4}$ and methanol $(90: 10, v / v)$, shaken for $0.5 \mathrm{~h}$ and then centrifuged for $15 \mathrm{~min}$ (3000 rpm). A $50-\mu \mathrm{l}$ aliquot of this solution was injected into the HPLC system. In the case of escitalopram, the procedure was similar with the exception that the extraction with an organic reagent $(3 \mathrm{ml})$ was repeated two times, $1 \mathrm{ml}$ of brain homogenate was used, and the volume of the acidic phase was $100 \mu$ l. Fluoxetine, paroxetine, and reboxetine were extracted from $200 \mu \mathrm{l}$ of serum after addition of the appropriate IS, $100 \mu \mathrm{l}$ of $4 \mathrm{M} \mathrm{NaOH}$, and $3 \mathrm{ml}$ of the extraction reagent. The procedure was repeated twice. In turn, to $1 \mathrm{ml}$ of brain homogenates containing these drugs, the IS was added and the samples were alkalized with $500 \mu \mathrm{l}$ of $4 \mathrm{M} \mathrm{NaOH}$. After the addition of $1 \mathrm{ml}$ of the concentrated $\mathrm{NaCl}$ solution $(10 \mathrm{~g} / 50 \mathrm{ml})$, the samples were vortexed for $15 \mathrm{~s}$ and $5 \mathrm{ml}$ of the extraction reagent was added. Then, serum samples and brain homogenates were shaken for $20 \mathrm{~min}$ and centrifuged for $15 \mathrm{~min}$ at $3000 \mathrm{rpm}$. After the centrifugation, the organic layer was transferred into a conical glass tube and evaporated to dryness at $37^{\circ} \mathrm{C}$ under a gentle stream of nitrogen in a water bath. The residue was dissolved with $100 \mu \mathrm{l}$ of methanol, and $50 \mu \mathrm{l}$ of this solution was injected into the HPLC system.

The HPLC system (Thermo Separation Products, San Jose, CA, USA) consisted of a P100 isocratic pump, a UV100 variable-wavelength UV/VIS detector, a Rheodyne 7125 injector (Rheodyne, Cotati, CA, USA) with a 50- $\mu$ l sample loop, and a Chromjet SP4400 computing integrator.

All analyses were performed on a $250 \times 4 \mathrm{~mm}$ LiChrospher ${ }^{\mathbb{Q}} 100$ RP-18 column with a particle size of $5 \mu \mathrm{m}$ (Merck, Darmstadt, Germany) protected with a guard column $(4 \times 4 \mathrm{~mm})$ with the same packing material. The mobile phase consisting of acetonitrile and $50 \mathrm{mM}$ potassium dihydrogen phosphate was mixed at a ratio of 60:40 $(v / v)$ for imipramine, 
desipramine, and fluoxetine and 65:35 (v/v) for escitalopram, paroxetine, and reboxetine and run at $1 \mathrm{ml} / \mathrm{min}$. Chromatographic analysis was carried out at $21{ }^{\circ} \mathrm{C}$, and the analytical wavelength of $227 \mathrm{~nm}$ for fluoxetine, $240 \mathrm{~nm}$ for escitalopram, and $214 \mathrm{~nm}$ for the remaining antidepressants studied.

The calibration curves constructed by plotting the ratio of the peak heights of the studied drug to IS versus concentration of the drug were linear in the tested concentration ranges. No interfering peaks were observed in the chromatograms. The assays were reproducible with low intra- and inter-day variation (coefficient of variation less than $10 \%$ ). The extraction efficiencies of the analyzed compounds and internal standards ranged from 66 to $97 \%$. Antidepressant concentrations were expressed in nanograms per milliliter of serum or nanograms per gram of wet brain tissue.

\section{Statistical analysis}

The statistical analysis of the results obtained in the FST and the locomotor activity assessment following caffeine administration was carried out using one-way ANOVA with Dunnett's post hoc test and after joint treatments using twoway ANOVA with Bonferroni's post hoc test. Interactions occurring between tested agents were analyzed with oneway ANOVA also with Bonferroni's post hoc test. The concentrations of the tested antidepressant drugs in blood and brains of mice in the presence and absence of caffeine were compared using Student's $t$ test. $p$ values less than or equal to 0.05 were considered statistically significant.

\section{Results}

\section{Caffeine dose-effect relationship in the FST}

In order to determine its antidepressant activity, caffeine was used in the following doses: 5, 10, 20, and $50 \mathrm{mg} / \mathrm{kg}$ (Fig. 1) [one-way ANOVA: $F(5,55)=8.536 ; p<0.0001$ ]. Statistical analysis of the results showed that caffeine used at a dose of $5 \mathrm{mg} / \mathrm{kg}$ had no statistically significant effect $(p>0.05)$ on the reduction of the immobility time in mice. However, caffeine administered at a dose of 10,20 , and $50 \mathrm{mg} / \mathrm{kg}$ significantly reduced the total time of immobility in comparison with the control group.

\section{The influence of caffeine on the antidepressant activity of tested drugs in the FST}

\section{Effect of combined administration of caffeine and imipramine in the FST}

The effect of the combined administration of caffeine and imipramine on the total duration of the immobility time in

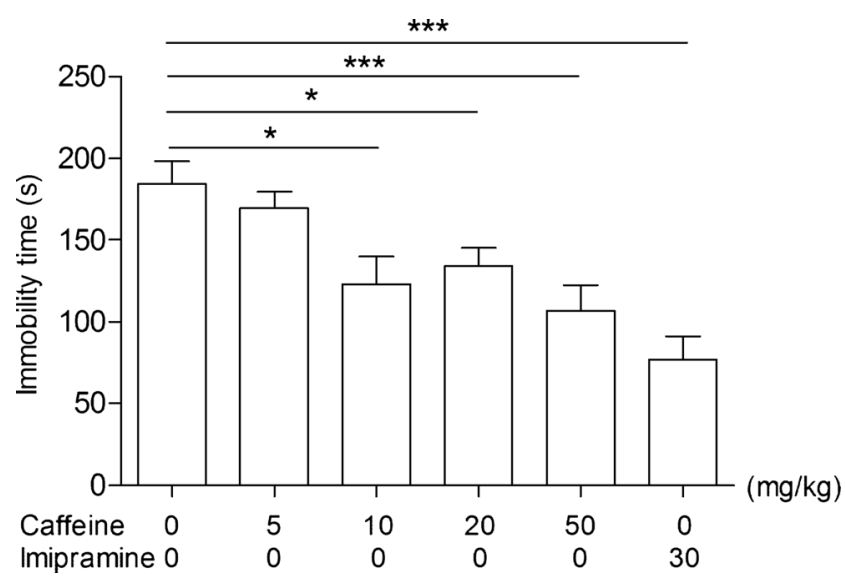

Fig. 1 The antidepressant activity of caffeine in the forced swim test in mice. Caffeine and saline were administered i.p. $40 \mathrm{~min}$, and imipramine i.p. $60 \mathrm{~min}$ before the test. The data are presented as the means \pm SEM. Each experimental group consisted of 10 animals. ${ }^{*} p<0.05,{ }^{* * *} p<0.001$ (one-way ANOVA followed by Dunnett's post hoc test)

mice is shown in Fig. 2a. Caffeine $(5 \mathrm{mg} / \mathrm{kg})$ injected in combination with imipramine $(15 \mathrm{mg} / \mathrm{kg})$ significantly reduced the immobility time in the FST in mice (Fig. 2a). We carried out analysis using two-way ANOVA followed by one-way ANOVA with Bonferroni's post hoc test.

Two-way ANOVA demonstrated an interaction between imipramine and caffeine $[F(1,28)=24.86, p<0.0001]$. Oneway ANOVAs followed by Bonferroni's post hoc test showed no effect of caffeine $(p>0.05)$ and no effect of imipramine $(p>0.05)$ alone. However, the effect of imipramine became significant in the presence of caffeine $(p<0.0001)$.

\section{Effect of combined administration of caffeine} and desipramine in the FST

The effect of the combined administration of caffeine and desipramine on the total duration of the immobility time in mice is shown in Fig. 2 b. Caffeine $(5 \mathrm{mg} / \mathrm{kg})$ injected in combination with desipramine $(10 \mathrm{mg} / \mathrm{kg})$ significantly reduced the immobility time in the FST in mice (Fig. 2b). We carried out analysis using two-way ANOVA followed by one-way ANOVA with Bonferroni's post hoc test.

Two-way ANOVA demonstrated an interaction between desipramine and caffeine $[F(1,35)=9.06, p<0.0048]$. Oneway ANOVAs followed by Bonferroni's post hoc test showed no effect of caffeine $(p>0.05)$ and no effect of desipramine $(p>0.05)$ alone. However, the effect of desipramine became significant in the presence of caffeine $(p<0.0001)$.

\section{Effect of combined administration of caffeine and fluoxetine} in the FST

The effect of the combined administration of caffeine and fluoxetine on the total duration of the immobility time in mice is shown in Fig. 2c. Caffeine $(5 \mathrm{mg} / \mathrm{kg})$ injected in 
Fig. 2 Effect of combined administration of caffeine and antidepressants in the forced swim test in mice. Caffeine was administered i.p. $40 \mathrm{~min}$, and all antidepressants and saline were administered i.p. $60 \mathrm{~min}$ before the test. The values represent mean \pm SEM. $(n=9-10$ per group). $* * * p<0.001$ (two-way ANOVA followed by Bonferroni's post hoc test). The control groups for imipramine and fluoxetine as well as desipramine and paroxetine are the same a

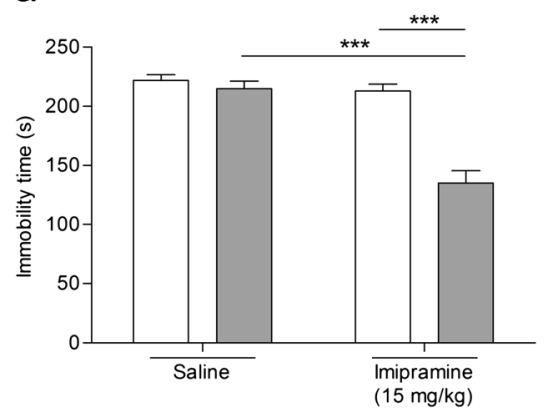

C

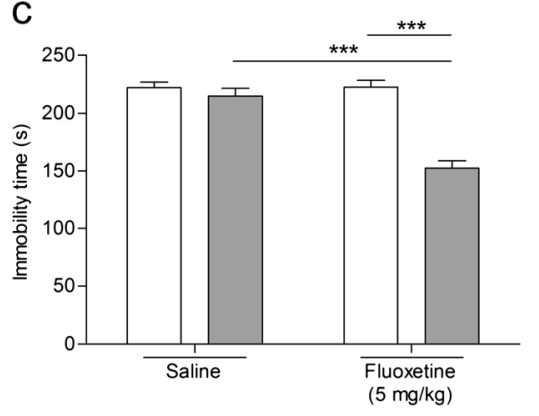

e

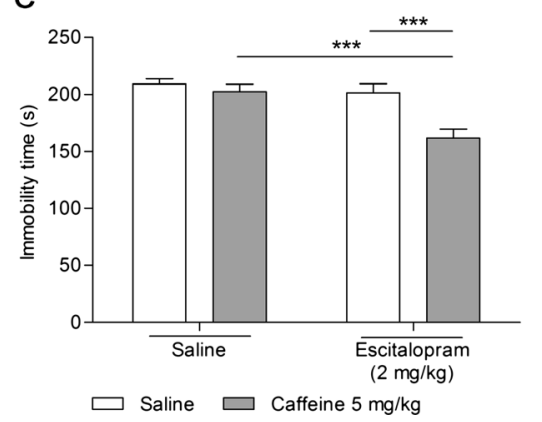

b

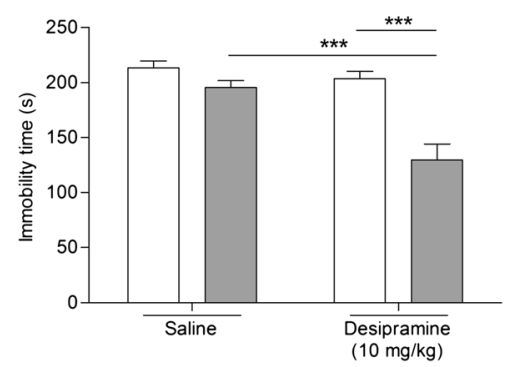

d

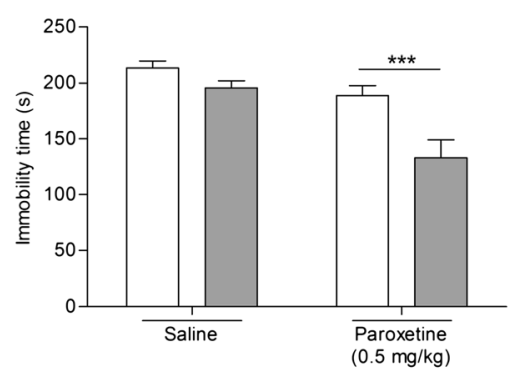

$f$

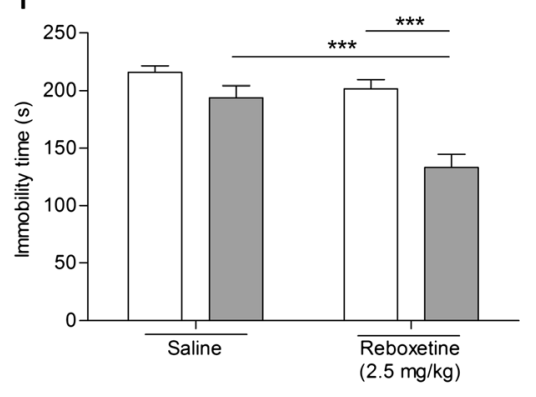

combination with fluoxetine $(5 \mathrm{mg} / \mathrm{kg})$ significantly reduced the immobility time in the FST in mice (Fig. 2c). We carried out analysis using two-way ANOVA followed by one-way ANOVA with Bonferroni's post hoc test.

Two-way ANOVA demonstrated an interaction between fluoxetine and caffeine $[F(1,28)=29.10, p<0.0001]$. Oneway ANOVAs followed by Bonferroni's post hoc test showed no effect of caffeine $(p>0.05)$ and no effect of fluoxetine $(p>0.05)$ alone. However, the effect of fluoxetine became significant in the presence of caffeine $(p<0.0001)$.

\section{Effect of combined administration of caffeine and paroxetine in the FST}

The effect of the combined administration of caffeine and paroxetine on the total duration of the immobility time in mice is shown in Fig. 2d. Two-way ANOVA demonstrated a lack of interaction between paroxetine and caffeine $[F(1,36)=3.45$, $p=0.0716]$, but a significant effect of paroxetine $[F(1,36)=$
$18.43, p=0.0001]$ and a significant effect of caffeine $[F(1$, 36) $=13.07, p=0.0009]$.

\section{Effect of combined administration of caffeine and escitalopram in the FST}

The effect of the combined administration of caffeine and escitalopram on the total duration of the immobility time in mice is shown in Fig. 2e. Caffeine $(5 \mathrm{mg} / \mathrm{kg})$ injected in combination with escitalopram $(2 \mathrm{mg} / \mathrm{kg})$ significantly reduced the immobility time in the FST in mice (Fig. 2e). We carried out analysis using two-way ANOVA followed by one-way ANOVA with Bonferroni's post hoc test.

Two-way ANOVA demonstrated an interaction between escitalopram and caffeine $[F(1,36)=5.88, p=0.0204]$. Oneway ANOVAs followed by Bonferroni's post hoc test showed no effect of caffeine $(p>0.05)$ and no effect of escitalopram $(p>0.05)$ alone. However, the effect of escitalopram became significant in the presence of caffeine $(p<0.0001)$. 
Effect of combined administration of caffeine and reboxetine in the FST

The effect of the combined administration of caffeine and reboxetine on the total duration of the immobility time in mice is shown in Fig. 2f. Caffeine ( $5 \mathrm{mg} / \mathrm{kg}$ ) injected in combination with reboxetine $(2.5 \mathrm{mg} / \mathrm{kg})$ significantly reduced the immobility time in the FST in mice (Fig. 2f). We carried out analysis using two-way ANOVA followed by one-way ANOVA with Bonferroni's post hoc test.

Two-way ANOVA demonstrated an interaction between reboxetine and caffeine $[F(1,35)=6.96, p=0.0124]$. One-way ANOVAs followed by Bonferroni's post hoc test showed no effect of caffeine $(p>0.05)$ and no effect of reboxetine $(p>0.05)$ alone. However, the effect of reboxetine became significant in the presence of caffeine $(p<0.0001)$.

\section{Effect of caffeine on locomotor activity in mice}

The effect of caffeine $(5,10,20$, and $50 \mathrm{mg} / \mathrm{kg})$ on spontaneous locomotor activity in mice is shown in Table 1 [one-way ANOVA, $F(4,35)=0.7440, p=0.5686]$. Statistical analysis of the results showed that caffeine used in all tested doses had no statistically significant effect on locomotor activity in mice versus control group.

\section{Effect of combined administration of caffeine and antidepressants on locomotor activity in mice}

The effect of the combined administration of caffeine and tested antidepressant drugs on spontaneous locomotor activity in mice is shown in Table 2. Caffeine or antidepressants (imipramine, fluoxetine, paroxetine, reboxetine, and escitalopram) administered either alone or combined together had no statistically significant effects on the locomotor activity in mice (Table 2). Desipramine administered alone had no significant effects on the locomotor activity in mice, while co-administered with caffeine

Table 1 Effect of caffeine on locomotor activity in mice

\begin{tabular}{ll}
\hline Treatment (mg/kg) & Distance traveled $(\mathrm{cm})$ \\
\hline Saline (control group) & $906.1 \pm 65.89$ \\
Caffeine 5 & $1087.0 \pm 53.00$ \\
Caffeine 10 & $1158.0 \pm 153.70$ \\
Caffeine 25 & $1144.0 \pm 136.20$ \\
Caffeine 50 & $1074.0 \pm 93.82$ \\
\hline
\end{tabular}

Caffeine and saline were administered i.p. $40 \mathrm{~min}$ before the test. Distance traveled was recorded between the second and the sixth minute of the test. The data are presented as the means \pm SEM. Each experimental group consisted of 7-8 animals. The results were considered statistically significant if $p<0.05$ (one-way ANOVA followed by Dunnett's post hoc test)
Table 2 Effect of treatments on spontaneous locomotor activity in mice

\begin{tabular}{|c|c|c|}
\hline & Treatment (mg/kg) & Distance traveled $(\mathrm{cm})$ \\
\hline \multirow[t]{6}{*}{ (A) } & Saline + saline & $637.6 \pm 53.12$ \\
\hline & Caffeine $5+$ saline & $663.9 \pm 35.96$ \\
\hline & Imipramine $15+$ saline & $621.4 \pm 77.17$ \\
\hline & Caffeine $5+$ imipramine 15 & $558.6 \pm 48.21$ \\
\hline & Fluoxetine $5+$ saline & $628.4 \pm 64.80$ \\
\hline & Caffeine $5+$ fluoxetine 5 & $643.7 \pm 95.11$ \\
\hline \multirow[t]{6}{*}{ (B) } & Saline + saline & $746.5 \pm 85.47$ \\
\hline & Caffeine $5+$ saline & $910.1 \pm 76.54$ \\
\hline & Desipramine $10+$ saline & $520.3 \pm 67.67$ \\
\hline & Caffeine $5+$ desipramine 10 & $539.8 \pm 31.14^{\wedge}$ \\
\hline & Paroxetine $0.5+$ saline & $759.0 \pm 97.15$ \\
\hline & Caffeine $5+$ paroxetine 0.5 & $967.3 \pm 124.6$ \\
\hline \multirow[t]{4}{*}{ (C) } & Saline + saline & $674.5 \pm 56.72$ \\
\hline & Caffeine $5+$ saline & $815.3 \pm 57.72$ \\
\hline & Escitalopram $2+$ saline & $794.5 \pm 75.21$ \\
\hline & Caffeine $5+$ escitalopram 2 & $802.0 \pm 73.10$ \\
\hline \multirow[t]{4}{*}{ (D) } & Saline + saline & $615.1 \pm 37.42$ \\
\hline & Caffeine $5+$ saline & $800.0 \pm 32.97$ \\
\hline & Reboxetine $2.5+$ saline & $505.3 \pm 78.64$ \\
\hline & Caffeine $5+$ reboxetine 2.5 & $696.0 \pm 68.45$ \\
\hline
\end{tabular}

Antidepressants and saline were administered i.p. $60 \mathrm{~min}$, and caffeine i.p. $40 \mathrm{~min}$ before the experiment. Distance traveled was recorded between the second and the sixth minute of the test. Each experimental group consisted of 7-8 animals. Data are presented as the means \pm SEM

${ }^{\wedge} p<0.01$ versus caffeine-treated group (two-way ANOVA followed by Bonferroni's post hoc test)

decreased the locomotor activity in mice in comparison with the control and caffeine-treated group [one-way ANOVA, $F(3,28)=7.309, p<0.001$ and $p<0.01$, respectively] (Table 2).

Two-way ANOVA demonstrated:

(A) No effect of imipramine $[F(1,25)=1.19, p=0.2857]$, no effect of caffeine $[F(1,25)=0.11, p=0.7450]$, and no interaction $[F(1,25)=0.64, p=0.4312]$.

(B) Extremely significant effect of desipramine $[F(1,28)=$ $19.02, p=0.0002]$, no effect of caffeine $[F(1,28)=1.79$, $p=0.1914]$, and no interaction $[F(1,28)=1.11, p=0.3011]$.

(C) No effect of fluoxetine $[F(1,26)=0.05, p=0.8237]$, no effect of caffeine $[F(1,26)=0.10, p=0.7527]$, and no interaction $[F(1,26)=0.01, p=0.9342]$.

(D) No effect of paroxetine $[F(1,28)=0.13, p=0.7241]$, no quite significant effect of caffeine $[F(1,28)=3.63, p=$ $0.0672]$, and no interaction $[F(1,28)=0.05, p=0.8209]$.

(E) No effect of escitalopram $[F(1,28)=0.65, p=0.4271]$, no effect of caffeine $[F(1,28)=1.25, p=0.2726]$, and no interaction $[F(1,28)=1.1, p=0.3231]$. 
(F) Very significant effect of reboxetine $[F(1,23)=9.95, p=$ $0.0044]$, not quite significant effect of caffeine $[F(1$, $23)=3.23, p=0.0857]$, and no interaction $[F(1,23)=$ $0.00, p=0.9612]$.

\section{Pharmacokinetic studies}

The effect of caffeine on serum and brain concentrations of the tested antidepressants in mice is shown in Tables 3 and 4. Only in the case of co-administration of caffeine and paroxetine an increased paroxetine concentration in serum was observed $(t$ test, $p=0.0296$ ) without affecting its concentration in the brain tissue. Conversely, caffeine lowered the concentration of imipramine in brain tissue ( $t$ test, $p=0.0207$ ) with no significant effect on its concentration in serum (Tables 3 and 4).

\section{Discussion}

Caffeine is one of the most commonly used psychoactive substances in the world (Solinas et al. 2002). Products containing caffeine have gained popularity due to the stimulant effect on the CNS. An excessive intake of caffeine is particularly prevalent amongst the patients hospitalized due to mental disorders. It is estimated that as many as $22 \%$ of these people consumed more than $750 \mathrm{mg}$ caffeine a day, whereas such a high intake of this methylxanthine was found in $9 \%$ of the

Table 3 Effect of caffeine on the concentrations of antidepressants in mouse serum

\begin{tabular}{lll}
\hline & Treatment & Drug concentration $(\mathrm{ng} / \mathrm{ml})$ \\
\hline (A) & Imipramine 15+saline & $352.4 \pm 72.13$ \\
& (Metabolite-desipramine) & $(34.69 \pm 6.17)$ \\
& Imipramine 15+caffeine 5 & $213.8 \pm 31.27$ \\
& (Metabolite-desipramine) & $(43.92 \pm 11.83)$ \\
(B) & Desipramine 10+saline & $203.7 \pm 22.54$ \\
& Desipramine 10+caffeine 5 & $220.6 \pm 25.05$ \\
(C) & Fluoxetine 5+ saline & $404.5 \pm 41.65$ \\
& Fluoxetine 5+caffeine 5 & $435.0 \pm 36.87$ \\
(D) & Paroxetine 0.5+ saline & $35.7 \pm 5.68$ \\
& Paroxetine 0.5+caffeine 5 & $63.9 \pm 10.50 *$ \\
(E) & Escitalopram 2+ saline & $81.1 \pm 3.40$ \\
& Escitalopram 2+caffeine 5 & $86.4 \pm 5.15$ \\
(F) & Reboxetine 2.5+saline & $211.0 \pm 23.05$ \\
& Reboxetine 2.5+caffeine 5 & $160.4 \pm 15.42$ \\
\hline
\end{tabular}

Antidepressants were administered i.p. $60 \mathrm{~min}$, and caffeine $40 \mathrm{~min}$ before decapitation. Each experimental group consisted of 9-10 animals. Results are presented as mean values \pm SEM

${ }^{*} p<0.05$ compared to the respective control group (Student's $t$ test)
Table 4 Effect of caffeine on the concentrations of antidepressants in mouse brain

\begin{tabular}{lll}
\hline & Treatment & Drug concentration $(\mathrm{ng} / \mathrm{g})$ \\
\hline (A) & Imipramine 15+saline & $5022.0 \pm 749.90$ \\
& (Metabolite-desipramine) & $(433.0 \pm 100.10)$ \\
& Imipramine 15+caffeine 5 & $2920.0 \pm 354.00^{*}$ \\
& (Metabolite-desipramine) & $(320.0 \pm 62.09)$ \\
(B) & Desipramine 10+saline & $2100.0 \pm 201.30$ \\
& Desipramine+caffeine 5 & $2455.0 \pm 259.40$ \\
(C) & Fluoxetine 5+ saline & $6091.0 \pm 484.90$ \\
& Fluoxetine 5+caffeine 5 & $6915.0 \pm 268.10$ \\
(D) & Paroxetine $0.5+$ saline & $129.5 \pm 9.78$ \\
& Paroxetine $0.5+$ caffeine 5 & $144.8 \pm 15.92$ \\
(E) & Escitalopram 2+ saline & $372.5 \pm 29.12$ \\
& Escitalopram 2+caffeine 5 & $371.2 \pm 31.17$ \\
(F) & Reboxetine 2.5+saline & $411.7 \pm 31.94$ \\
& Reboxetine 2.5 + caffeine 5 & $378.8 \pm 34.06$ \\
\hline
\end{tabular}

Antidepressants were administered i.p. $60 \mathrm{~min}$, and caffeine $40 \mathrm{~min}$ before decapitation. Each experimental group consisted of 10 animals. Results are presented as mean values \pm SEM

${ }^{*} p<0.05$ compared to the respective control group (Student's $t$ test)

general population (Hughes et al. 1998). Caffeine acts on the CNS both directly and indirectly. In non-toxic doses, caffeine acts mainly as an antagonist of adenosine inhibitory $A_{1}$ and stimulatory $\mathrm{A}_{2 \mathrm{~A}}$ receptors and these receptors control the neuronal excitability and the release of several neurotransmitters, including ACh, DA, NA, and 5-HT. Only in higher doses caffeine is capable to inhibit the activity of phosphodiesterases and GABA receptors or mobilize intracellular $\mathrm{Ca}^{2+}$ (Fredholm 1995; Goldberg et al. 1982; Lorist and Tops 2003; Williams 1987).

Numerous animal studies indicate that psychostimulantactive compounds such as caffeine or amphetamine reduce the duration of immobility time in the FST (EnríquezCastillo et al. 2008; Gan et al. 2009; Vieira et al. 2008), and the observed effect is comparable with the one recorded after administration of tricyclic antidepressants (i.e., imipramine, desipramine), SSRIs (i.e., fluoxetine, paroxetine, or sertraline), and SNRIs (Page et al. 1999). Other adenosine receptor antagonists, e.g., istradefylline (KW 6002) (El Yacoubi et al. 2003; El Yacoubi et al. 2001; Yamada et al. 2013), and SCH 58261 (El Yacoubi et al. 2003; El Yacoubi et al. 2001) exerted an antidepressant-like activity in the FST and the tail suspension test (TST), as well.

However, according to the literature (Batalha et al. 2013; Pechlivanova et al. 2012) (Lucas et al. 2011; Smith 2002), caffeine affects mood of animals and humans in a dose-dependent manner. A low dose of this methylxanthine $(10 \mathrm{mg} / \mathrm{kg})$ reduces the duration of immobility time of rodents in the FST, while its high dose $(100 \mathrm{mg} / \mathrm{kg})$ produces the opposite effect (Gan et al. 
2009). Also, El Yacoubi et al. showed that caffeine at stimulant doses was effective in FST (El Yacoubi et al. 2003). It is believed that the influence on catecholamines and 5-HT neurotransmission is responsible for the response observed after administration of the low dose of caffeine (Rénéric and Lucki 1998). An injection of the higher dose is probably related to an excessive increase in the level of ACh and 5-HT in the CNS, which leads to the inhibition of adenosine receptors (Nikodijević et al. 1993a; Nikodijević et al. 1993b). What is more, in their most recent research, Kaster et al. showed protective effects of caffeine on maladaptive changes in the model of chronic unpredictable stress, which was comparable with the selective blocking of adenosine $\mathrm{A}_{2 \mathrm{~A}}$ receptors. This study pointed out that adenosine $A_{2 A}$ receptor blockers have therapeutic benefits and their use should be considered as a novel therapy to counteract the negative impact of chronic stress on mood (Kaster et al. 2015). The results of our study confirmed the antidepressant-like activity of caffeine given at the doses of 10 , 20 , and $50 \mathrm{mg} / \mathrm{kg}$. Moreover, the highest dose used by us exerted an effect similar to the action of imipramine administered at an active dose $(30 \mathrm{mg} / \mathrm{kg})$.

We also demonstrated that caffeine may affect the action of typical antidepressant drugs, such as imipramine, desipramine, fluoxetine, escitalopram, paroxetine, and reboxetine. Co-administration of caffeine with these agents at the non-active doses resulted in a statistically significant reduction in the immobility times in the FST compared with the control groups. It should be noted that the observed effects were not due to the increase in locomotor activity of animals. Most probably, the shorter immobility time noted after the joint administration of caffeine and imipramine or desipramine may be a consequence of the enhancement of NA and 5-HT transduction (Lorden and Nunn 1982). Caffeine influences $A_{1}$ receptors, which are located on serotonergic neurons in the dorsal nucleus structures (Mössner et al. 2000) and in the locus coeruleus (Regenold and Illes 1990). It is known that the stimulation by endogenous adenosine or adenosine selective agonists causes a reduction in the activity of serotonergic neurons (Regenold and Illes 1990), which leads to a decrease in the adrenergic and serotonergic transmission (Okada et al. 2002). Caffeine through antagonism of the $A_{1}$ receptors, inter alia, blocks the effects of endogenous adenosine and increases NA and 5-HT transduction in the CNS (Fredholm et al. 1999; Kulkarni and Mehta 1985; Schlosberg 1984), which may explain the synergistic effect on the performance of the tested TCAs. Another cause of the synergistic effect of caffeine and imipramine or desipramine may be an impaired metabolism of caffeine by these antidepressants. It has been shown that both imipramine and desipramine inhibit the demethylation and hydroxylation of caffeine which reduces the elimination of caffeine from the organism (Daniel et al. 2003). In the research published by Robles-Molina (2012), the concurrent administration of caffeine and desipramine did not change the locomotor activity of animals, while we noticed their hypolocomotion. However, such a discrepancy might arise due to the application of different doses of the tested substances $(0.31,1 \mathrm{mg} / \mathrm{kg}$ of caffeine and $0.31,1$, $3.1 \mathrm{mg} / \mathrm{kg}$ of desipramine versus $5 \mathrm{mg} / \mathrm{kg}$ of caffeine and $10 \mathrm{mg} / \mathrm{kg}$ of desipramine) and different strains of mice (BALB/c versus Albino Swiss).

As demonstrated in the present study, caffeine augmented the activity of the SSRI agents, which is a group of drugs that are currently the first choice in the treatment of depressive disorders. They are characterized by a safer profile of adverse reactions compared with other antidepressants, and consequently, they are better tolerated by patients. The recorded synergy can also be explained by the inhibitory effect of caffeine on the effects of endogenous adenosine, which decreases the release of many neurotransmitters in the CNS, including 5HT (Mössner et al. 2000). This blockage leads to an increase in the amount of 5-HT in the synapse and modulation of the serotoninergic transmission. Our observations are consistent with the previous reports on this subject. For example, it was shown that the administration of caffeine in the diet of rats causes an increase in the concentration of 5-HT, 5hydroxyindoleacetic acid (a breakdown product of 5-HT), and tryptophan (the starting material for the production of 5HT) in the CNS (Yokogoshi et al. 1987). A similar effect was observed in rats after the administration of caffeine i.p. at doses of $10-100 \mathrm{mg} / \mathrm{kg}$ (Fernstrom et al. 1984; Haleem et al. 1995). In vitro studies have also shown increased levels of 5HT in biological material (brain stem, brain, and cerebellum) collected from rats after administration of caffeine (Berkowitz and Spector 1971; Stromberg and Waldeck 1973).

As previously mentioned, caffeine is supposed to enhance a release of NA in the CNS (Williams 1987). However, the research involving methylxanthines (including caffeine) showed conflicting results in terms of their impact on the level of catecholamines. On the one hand, it has been demonstrated that methylxanthines do not affect the concentration of NA in the CNS of rats (Karasawa et al. 1976; Schlosberg 1984); on the other hand, it has been reported that they stimulate the metabolism and the release of catecholamines in the brain (Atkinson and Enslen 1976; Costill et al. 1978). The enhancement of anti-immobility action of reboxetine by caffeine coadministration observed in our study is probably related to an increased amount of NA in the CNS. As mentioned before, reboxetine blocks neuronal reuptake of NA and the level of this neurotransmitter rises in the CNS. Caffeine, due to antagonism of adenosine receptors, also increases the release of NA, which has been observed in preclinical studies and clinical trials; after administration of single doses of caffeine, increased levels of NA were observed in blood and urine in humans (Benowitz 1990; Papadelis et al. 2003) and in blood 
and brains of laboratory animals (Bender and Bobrova 1982; Goldberg et al. 1982).

Hydrophobic properties of caffeine allow its easy penetration through all biological membranes. It is distributed to all body fluids - plasma, cerebrospinal fluid, saliva, bile, semen, milk, umbilical cord blood, and organ tissues (Arnaud 2011). Almost all of caffeine is present in a pharmacologically active form, since the fraction bound to plasma proteins is relatively small (McCall et al. 1982). Pharmacokinetic studies carried out in the present research were aimed at assessing concentrations of antidepressants in blood and brain of mice after their combined administration with caffeine and estimating the nature of the agent-agent interactions. The present work is also the first in which such an attempt was made. The existing data on changes in the therapeutic effect of antidepressants caused by concomitant administration of caffeine were based solely on the results obtained in behavioral tests (Kale and Addepalli 2014; Robles-Molina et al. 2012). The available literature emphasizes the role of CYP1A2, the main enzyme responsible for the metabolism of caffeine, in the metabolism of drugs from different therapeutic groups, including antidepressants (e.g., imipramine, mianserin, amitriptyline, or fluvoxamine). Clinically significant pharmacokinetic interactions between caffeine and these substances is related to the amount and activity of this isoenzyme (Lin and Lu 1998; Pelkonen et al. 1998). We found that caffeine does not affect the concentrations of most of the tested antidepressants (desipramine, fluoxetine, escitalopram, reboxetine) either in serum or brain tissue. These results suggest that interactions observed between caffeine and these drugs presumably are pharmacodynamic, which refers to changes at the cellular level. We reported a statistically significant reduction in the amount of imipramine in brain tissue, with no statistically significant changes in serum drug concentration after a concurrent administration with caffeine. It is possible that the observed alterations were associated with the modifications in the biotransformation of imipramine, since both caffeine and imipramine are metabolized by the same isoenzyme of cytochrome P450 (Carrillo and Benitez 2000) or imipramine transport through bloodbrain barrier. The interplay between caffeine and paroxetine demonstrated in the course of our study is not entirely clear. As a result of the joint administration of these agents, there has been an increase in the serum concentration of paroxetine, but concentration changes in the brain, which is the target site of action of antidepressants, have not been observed. In the case of drugs acting on the CNS, the concentration of drug in the brain structures is responsible for the pharmacological effect. However, the question of the correlation between the drug concentration in blood and CNS is controversial. It is believed that changes in the serum level should reflect changes occurring in the amount of drug in the brain tissue. No such relationship may be due to the delay in the transport of the drug through the blood-brain barrier (Burke and Preskorn 2004).
Accordingly, it can be concluded that the interaction between caffeine and paroxetine takes place in the pharmacokinetic phase. Both observed pharmacokinetic interactions could have important consequences for patients that are coffee drinkers or otherwise caffeine users under imipramine or paroxetine therapy.

\section{Conclusions}

In summary, we confirmed that caffeine produced an antidepressant-like effect and demonstrated a caffeineinduced enhancement of the antidepressant effect of imipramine, desipramine, fluoxetine, paroxetine, escitalopram, and reboxetine in the Porsolt's test without stimulation of locomotor activity. The interplay between the tested methylxanthine and desipramine, fluoxetine, escitalopram, and reboxetine seems to be exclusively pharmacodynamic in nature, whereas an increased antidepressant activity of paroxetine or imipramine was at least partly related to their pharmacokinetic interaction with caffeine. However, when formulating conclusions concerning the type of the observed interactions on the basis of the pharmacokinetic studies, one should be particularly careful, since biotransformation of drugs may proceed differently in animals and humans.

Acknowledgments This study was supported by Funds for Statutory Activity of Medical University of Lublin, Poland (grant number MNmb18/2012-2014).

\section{Compliance with ethical standard}

Ethical approval All procedures were conducted in accordance with the European Communities Council Directive of 22 September 2010 (2010/63/EU) and Polish legislation acts concerning animal experimentations. The experimental procedures and protocols were approved by the First Local Ethics Committee at the Medical University of Lublin.

Conflict of interest The authors declare that they have no competing interests.

Open Access This article is distributed under the terms of the Creative Commons Attribution 4.0 International License (http:// creativecommons.org/licenses/by/4.0/), which permits unrestricted use, distribution, and reproduction in any medium, provided you give appropriate credit to the original author(s) and the source, provide a link to the Creative Commons license, and indicate if changes were made.

\section{References}

Acquas E, Tanda G, Di CG (2002) Differential effects of caffeine on dopamine and acetylcholine transmission in brain areas of drug-naive and caffeine-pretreated rats. Neuropsychopharmacology 27:182-193

Andrews KW, Schweitzer A, Zhao C, Holden JM, Roseland JM, Brandt M, Dwyer JT, Picciano MF, Saldanha LG, Fisher KD, Yetley E, Betz 
JM, Douglass L (2007) The caffeine contents of dietary supplements commonly purchased in the US: analysis of 53 products with caffeine-containing ingredients. Anal Bioanal Chem 389:231-239

Arnaud MJ (2011) Pharmacokinetics and metabolism of natural methylxanthines in animal and man. In: Fredholm BB (ed) Methylxanthines. Springer-Verlag, Heidelberg, pp 35-93

Atkinson J, Enslen M (1976) Self-administration of caffeine by the rat. Arzneimittelforschung 26:2059-2061

Barone JJ, Roberts HR (1996) Caffeine consumption. Food Chem Toxicol 34:119-129

Batalha VL, Pego JM, Fontinha BM, Costenla AR, Valadas JS, Baqi Y, Radjainia H, Müller CE, Sebastião AM, Lopes LV (2013) Adenosine $\mathrm{A}_{2 \mathrm{~A}}$ receptor blockade reverts hippocampal stressinduced deficits and restores corticosterone circadian oscillation. Mol Psychiatry 18:320-331

Bender KI, Bobrova LA (1982) Monoamine content of the blood in the experimental pharmacotherapy of alcoholic intoxication. Farmakol Toksikol 45:71-75

Benowitz NL (1990) Clinical pharmacology of caffeine. Annu Rev Med 41:277-288

Berkowitz BA, Spector S (1971) The effect of caffeine and theophylline on the disposition of brain serotonin in the rat. Eur J Pharmacol 16: 322-325

Burke LM (2008) Caffeine and sports performance. Appl Physiol Nutr Metab 33:1319-1334

Burke MJ, Preskorn SH (2004) Therapeutic drug monitoring of antidepressants. In: Preskorn SH, Feigher JP, Stanga CY, Ross R (eds) Antidepressants: past, present and future. Springer-Verlag, Heidelberg, pp 87-117

Carrillo JA, Benitez J (2000) Clinically significant pharmacokinetic interactions between dietary caffeine and medications. Clin Pharmacokinet 39:127-153

Casas M, Ramos-Quiroga JA, Prat G, Qureshi A (2004) Effects of coffee and caffeine on mood and mood disorders. In: Nehlig A (ed) Coffee, tea, chocolate, and the brain. CRC Press, New York, pp 79-89

Costill DL, Dalsky GP, Fink WJ (1978) Effects of caffeine ingestion on metabolism and exercise performance. Med Sci Sports 10:155-158

Daniel WA, Kot M, Wójcikowski J (2003) Effects of classic and newer antidepressants on the oxidation pathways of caffeine in rat liver. In vitro study. Pol J Pharmacol 55:1045-1053

David DJ, Bourin M, Jego G, Przybylski C, Jolliet P, Gardier AM (2003) Effects of acute treatment with paroxetine, citalopram and venlafaxine in vivo on noradrenaline and serotonin outflow: a microdialysis study in Swiss mice. Br J Pharmacol 140:1128-1136

Dunwiddie TV, Masino SA (2001) The role and regulation of adenosine in the central nervous system. Annu Rev Neurosci 24:31-55

El Yacoubi M, Ledent C, Parmentier M, Bertorelli R, Ongini E, Costentin J, Vaugeois JM (2001) Adenosine $\mathrm{A}_{2 \mathrm{~A}}$ receptor antagonists are potential antidepressants: evidence based on pharmacology and $\mathrm{A}_{2 \mathrm{~A}}$ receptor knockout mice. Br J Pharmacol 134:68-77

El Yacoubi M, Costentin J, Vaugeois JM (2003) Adenosine $\mathrm{A}_{2 \mathrm{~A}}$ receptors and depression. Neurology 61:S82-S87

Enríquez-Castillo A, Alamilla J, Barral J, Gourbière S, Flores-Serrano AG, Góngora-Alfaro JL, Pineda JC (2008) Differential effects of caffeine on the antidepressant-like effect of amitriptyline in female rat subpopulations with low and high immobility in the forced swimming test. Physiol Behav 94:501-509

Fernstrom MH, Bazil CW, Fernstrom JD (1984) Caffeine injection raises brain tryptophan level, but does not stimulate the rate of serotonin synthesis in rat brain. Life Sci 35:1241-1247

Ferré S, O'Connor WT, Svenningsson P, Björklund L, Lindberg J, Tinner B, Strömberg I, Goldstein M, Ögren SO, Ungerstedt U, Fredholm BB, Fuxe K (1996a) Dopamine $\mathrm{D}_{1}$ receptor-mediated facilitation of GABAergic neurotransmission in the rat strioentopenduncular pathway and its modulation by adenosine $\mathrm{A}_{1}$ receptor-mediated mechanisms. Eur J Neurosci 8:1545-1553
Ferré S, Popoli P, Tinner-Staines B, Fuxe K (1996b) Adenosine $\mathrm{A}_{1}$ receptor-dopamine $\mathrm{D}_{1}$ receptor interaction in the rat limbic system: modulation of dopamine $D_{1}$ receptor antagonist binding sites. Neurosci Lett 208:109-112

Fisone G, Borgkvist A, Usiello A (2004) Caffeine as a psychomotor stimulant: mechanism of action. Cell Mol Life Sci 61:857-872

Fredholm BB (1995) Astra Award Lecture. Adenosine, adenosine receptors and the actions of caffeine. Pharmacol Toxicol 76:93-101

Fredholm BB, Bättig K, Holmén J, Nehlig A, Zvartau EE (1999) Actions of caffeine in the brain with special reference to factors that contribute to its widespread use. Pharmacol Rev 51:83-133

Gan SH, Ramli N, Mukiar N (2009) Dual effects of low and high dose caffeine. Lat Am J Pharm 28:465-469

Goldberg MR, Curatolo PW, Tung CS, Robertson D (1982) Caffeine downregulates $\beta$ adrenoreceptors in rat forebrain. Neurosci Lett 31:47-52

Haleem DJ, Yasmeen A, Haleem MA, Zafar A (1995) 24h withdrawal following repeated administration of caffeine attenuates brain serotonin but not tryptophan in rat brain: implications for caffeineinduced depression. Life Sci 57:L285-L292

Hughes JR, Oliveto AH, Liguori A, Carpenter J, Howard T (1998) Endorsement of DSM-IV dependence criteria among caffeine users. Drug Alcohol Depend 52:99-107

Kale PP, Addepalli V (2014) Augmentation of antidepressant effects of duloxetine and bupropion by caffeine in mice. Pharmacol Biochem Behav 124:238-244

Karasawa T, Furukawa K, Yoshida K, Shimizu M (1976) Effect of theophylline on monoamine metabolism in the rat brain. Eur $\mathrm{J}$ Pharmacol 37:97-104

Kaster MP, Machado NJ, Silva HB, Nunes A, Ardais AP, Santana M, Baqi Y, Müller CE, Rodrigues AL, Porciúncula LO, Chen JF, Tomé AR, Agostinho P, Canas PM, Cunha RA (2015) Caffeine acts through neuronal adenosine $\mathrm{A}_{2 \mathrm{~A}}$ receptors to prevent mood and memory dysfunction triggered by chronic stress. Proc Natl Acad Sci U S A 112:7833-7838

Kulkarni SK, Mehta AK (1985) Purine nucleoside-mediated immobility in mice: reversal by antidepressants. Psychopharmacology (Berl) 85:460-463

Lin JH, Lu AY (1998) Inhibition and induction of cytochrome P450 and the clinical implications. Clin Pharmacokinet 35:361-390

Lorden JF, Nunn WB (1982) Effects of central and peripheral pretreatment with fluoxetine in gustatory conditioning. Pharmacol Biochem Behav 17:435-443

Lorist MM, Tops M (2003) Caffeine, fatigue, and cognition. Brain Cogn 53:82-94

Lucas M, Mirzaei F, Pan A, Okereke OI, Willett WC, O'Reilly ÉJ, Koenen K, Ascherio A (2011) Coffee, caffeine, and risk of depression among women. Arch Intern Med 171:1571-1578

McCall AL, Millington WR, Wurtman RJ (1982) Blood-brain barrier transport of caffeine: dose-related restriction of adenine transport. Life Sci 31:2709-2715

Mössner R, Albert D, Persico AM, Hennig T, Bengel D, Holtmann B, Schmitt A, Keller F, Simantov R, Murphy D, Seif I, Deckert J, Lesch $\mathrm{KP}$ (2000) Differential regulation of adenosine $A_{1}$ and $A_{2 A}$ receptors in serotonin transporter and monoamine oxidase A-deficient mice. Eur Neuropsychopharmacol 10:489-493

Nehlig A, Daval JL, Debry G (1992) Caffeine and the central nervous system: mechanisms of action, biochemical, metabolic and psychostimulant effects. Brain Res Brain Res Rev 17:139-170

Nikodijević O, Jacobson KA, Daly JW (1993a) Effects of combinations of methylxanthines and adenosine analogs on locomotor activity in control and chronic caffeine-treated mice. Drug Dev Res 30:104-110

Nikodijević O, Jacobson KA, Daly JW (1993b) Locomotor activity in mice during chronic treatment with caffeine and withdrawal. Pharmacol Biochem Behav 44:199-216 
Okada M, Zhu G, Yoshida S, Iwasa H, Kaneko S (2002) Mechanisms of interaction between adenosine receptor subtypes on hippocampal serotonin release. Nihon Shinkei Seishin Yakurigaku Zasshi 22:61-69

Page ME, Detke MJ, Dalvi A, Kirby LG, Lucki I (1999) Serotonergic mediation of the effects of fluoxetine, but not desipramine, in the rat forced swimming test. Psychopharmacology (Berl) 147:162-167

Papadelis C, Kourtidou-Papadeli C, Vlachogiannis E, Skepastianos P, Bamidis P, Maglaveras N, Pappas K (2003) Effects of mental workload and caffeine on catecholamines and blood pressure compared to performance variations. Brain Cogn 51:143-154

Pechlivanova DM, Tchekalarova JD, Alova LH, Petkov VV, Nikolov RP, Yakimova KS (2012) Effect of long-term caffeine administration on depressive-like behavior in rats exposed to chronic unpredictable stress. Behav Pharmacol 23:339-347

Pelkonen O, Mäenpää J, Taavitsainen P, Rautio A, Raunio H (1998) Inhibition and induction of human cytochrome P450 (CYP) enzymes. Xenobiotica 28:1203-1253

Pettenuzzo LF, Noschang C, von Pozzer TE, Fachin A, Vendite D, Dalmaz C (2008) Effects of chronic administration of caffeine and stress on feeding behavior of rats. Physiol Behav 95:295-301

Poleszak E, Wlaź P, Kędzierska E, Nieoczym D, Wyska E, SzymuraOleksiak J, Fidecka S, Radziwoń-Zaleska M, Nowak G (2006) Immobility stress induces depression-like behavior in the forced swim test in mice: effect of magnesium and imipramine. Pharmacol Rep 58:746-752

Porsolt RD, Bertin A, Jalfre M (1977) Behavioral despair in mice: a primary screening test for antidepressants. Arch Int Pharmacodyn Ther 229:327-336

Regenold JT, Illes P (1990) Inhibitory adenosine $A_{1}$-receptors on rat locus coeruleus neurones. An intracellular electrophysiological study. Naunyn Schmiedebergs Arch Pharmacol 341:225-231

Rénéric JP, Lucki I (1998) Antidepressant behavioral effects by dual inhibition of monoamine reuptake in the rat forced swimming test. Psychopharmacology (Berl) 136:190-197

Rihs M, Muller C, Baumann P (1996) Caffeine consumption in hospitalized psychiatric patients. Eur Arch Psychiatry Clin Neurosci 246:83-92

Robles-Molina E, Millán D, Hong E, Huang F, Villafaña S (2012) Increased antidepressant-like effect of desipramine combined with central stimulants (caffeine and amphetamine) in mice. Centr Eur J Biol 7:391-396

Schlosberg AJ (1984) Acute and chronic effects of caffeine on brain monoamine levels and endocrine function in the rat. Arch Int Pharmacodyn Ther 267:149-160

Shapiro RE (2007) Caffeine and headaches. Neurol Sci 28(Suppl 2): S179-S183

Smith A (2002) Effects of caffeine on human behavior. Food Chem Toxicol 40:1243-1255

Solinas M, Ferré S, You ZB, Karcz-Kubicha M, Popoli P, Goldberg SR (2002) Caffeine induces dopamine and glutamate release in the shell of the nucleus accumbens. J Neurosci 22:6321-6324

Stromberg U, Waldeck B (1973) Behavioural and biochemical interaction between caffeine and L-dopa. J Pharm Pharmacol 25:302-308

Szewczyk B, Brański P, Wierońska JM, Pałucha A, Pilc A, Nowak G (2002) Interaction of zinc with antidepressants in the forced swimming test in mice. Pol J Pharmacol 54:681-685

Szewczyk B, Poleszak E, Wlaź P, Wróbel A, Blicharska E, Cichy A, Dybała M, Siwek A, Pomierny-Chamioło L, Piotrowska A, Brański P, Pilc A, Nowak G (2009) The involvement of serotonergic system in the antidepressant effect of zinc in the forced swim test. Prog Neuropsychopharmacol Biol Psychiatry 33:323-329

Urani A, Roman FJ, Phan VL, Su TP, Maurice T (2001) The antidepressant-like effect induced by $\sigma_{1}$-receptor agonists and neuroactive steroids in mice submitted to the forced swimming test. J Pharmacol Exp Ther 298:1269-1279

Vieira C, De Lima TC, Carobrez AP, Lino-de-Oliveira C (2008) Frequency of climbing behavior as a predictor of altered motor activity in rat forced swimming test. Neurosci Lett 445:170-173

Williams M (1987) Purine receptors in mammalian tissues: pharmacology and functional significance. Annu Rev Pharmacol Toxicol 27:315-345

Yamada K, Kobayashi M, Mori A, Jenner P, Kanda T (2013) Antidepressant-like activity of the adenosine $\mathrm{A}_{2 \mathrm{~A}}$ receptor antagonist, istradefylline (KW-6002), in the forced swim test and the tail suspension test in rodents. Pharmacol Biochem Behav 114-115:23-30

Yokogoshi H, Iwata T, Ishida K, Yoshida A (1987) Effect of amino acid supplementation to low protein diet on brain and plasma levels of tryptophan and brain 5-hydroxyindoles in rats. J Nutr 117:42-47 